Archives of Agriculture and Environmental Science

\title{
Communication exposure of sub-assistant agriculture officers (SAAOs) towards e-agriculture in Khulna district of Bangladesh
}

\author{
Avijit Biswas $^{1^{*}}$ (D) , A.T.M. Sanaul Haque ${ }^{2}$, Md Golam Rabbani Akanda ${ }^{2}$ and Prome Debnath ${ }^{3}$ \\ ${ }^{1}$ Department of Agriculture, Bangabandhu Sheikh Mujibur Rahman Science and Technology University, Gopalganj, BANGLADESH \\ ${ }^{2}$ Department of Agricultural Extension and Rural Development, Patuakhali Science and Technology University, Patuakhali, \\ BANGLADESH \\ ${ }^{3}$ Department of Disaster Risk Management, Patuakhali Science and Technology University, Patuakhali, BANGLADESH \\ *Corresponding author's E-mail: avijitpstu@gmail.com
}

\section{ARTICLE HISTORY}

Received: 25 August 2019

Revised received: 30 October 2019

Accepted: 20 November 2019

\section{Keywords}

Agricultural extension

Communication exposure

E-agriculture

ICTs

SAAO

\section{ABSTRACT}

The purpose of this study was to determine the extent of communication exposure of the Sub-Assistant Agriculture Officers towards e-agriculture in Khulna district of Bangladesh. Study was conducted in the five selected upazilas of Khulna city viz., Rupsa, Dighalia, Phultala, Dumuria and Batiaghata which consist of 108 agricultural blocks. A sample of 100 Sub-Assistant Agriculture Officers (SAAOs) was selected from these blocks. Data were collected following a structured pretested interview schedule. Findings revealed that most $60 \%$ of the SAAOs had low communication exposures to e-agriculture. Correlation analysis indicates that age, income and service experience had negative significant relationship with communication exposures of SAAOs to e-Agriculture. T raining exposure and knowledge on e-agriculture had positive significant relationship with their communication exposures towards e-agriculture. The enter method of regression analysis revealed that knowledge on e-agriculture, training exposure and monthly income described 77.5 percent variation in the communication exposure of SAAOs. The estimates indicated that knowledge on e-Agriculture had strongest $(\beta=0.479)$ contribution to the variance of communication exposure to e-Agriculture. On the other hand, monthly income had contributed to the variance of communication exposure of SAAOs towards e-Agriculture in negative direction $(\beta=-0.156)$. Mobile phone was the highest preferred device in using e-Agricultural media by the SAAOs. "Unfamiliarity of extension workers with e-agriculture application" was the main personal constraint and "lack of training on e-agriculture" was the main organizational constraint which might have led to low communication exposure of SAAOs towards e-agriculture.

(C)2019 Agriculture and Environmental Science Academy

Citation of this article: Biswas, A., Haque, A.T.M.S., Akanda, M.G.R. and Debnath, P. (2019). Communication exposure of sub-assistant agriculture officers (SAAOs) towards e-agriculture in Khulna district of Bangladesh. Archives of Agriculture and Environmental Science, 4(4): 434-441, https://dx.doi.org/10.26832/24566632.2019.0404010

\section{INTRODUCTION}

Bangladesh is an agrarian country and agriculture is the backbone of its economy where more than $60 \%$ land is used for cultivation (Ahmed, 2007). The national economy of Bangladesh is primarily based on agriculture and more than $80 \%$ of the total populations are directly or indirectly engaged in a wide range of agricultural activities. Agriculture sector contributes about $15.89 \%$ of GDP for her national economy (BBS, 2014). As now-a -days decreasing availability of natural resources but the agricultural sector is confronted with the major challenge of increasing production to feed a huge population (Bhalekar et al., 2015). However, the growing demand, including for higher quality products, also offers opportunities for improving the livelihoods of rural communities (Bhalekar et al., 2015). But to enhance the livelihoods of the rural population, new approaches and technical innovations are required to cope with these challenges. In this regard information and communication 
technology (ICT) plays a vital role in agricultural development by providing fast and relevant information to the end users (Reddy, 2012) and different government and non-government organizations that have been working in this field (Jensen, 2007) by practicing e-agriculture. E-Agriculture has been defined as an emerging field for enhancing sustainable agriculture and food security through technology dissemination and delivering information by using Internet and related technologies (Ghogare and Monga, 2015). More specifically, it involves the conceptualization, design, development, evaluation and application of new (innovative) ways to use existing or emerging information and communication technologies (ICTs) (Singh et al., 2015; Ghogare and Monga, 2015). ICTs can speed up agricultural technology transfer from research and development institutions to farmers (Joyous and Paul, 2016). ICTs improve adoption of agricultural technology by supporting farmer learning, problem solving and accessibility to profitable markets for their crops (World Bank, 2011). Asfaw et al. (2012) argue that development of agriculture can only be possible through the dissemination of improved agricultural technologies and information to the farmers in the rural area. In Bangladesh all agricultural information and recommended technologies are being disseminated to grass-root level by Department of Agricultural Extension (DAE) especially by the extension workers who are designated as Sub-Assistant Agriculture Officer (SAAO). The information needs of farmers will increase in the changing context of agriculture as they must make more and more complex decisions that impact the livelihoods of their families and society (FAO, 2015). Agricultural extension is a service or system which increases the knowledge of farmers through educational procedures, it helps to improve farming methods and techniques, increase farmer's income and raise the living standards of rural life. Agricultural extension could be considered as a connector between the information of scientists and Governmental bodies and agricultural practice or farming (Timmer, 1982). The farmer's desired agricultural information is required on urgent basis; the Sub-Assistant Agriculture Officer (SAAO) can access e-agriculture to obtain the necessary agricultural information from the concerned person or the authentic source in a short time. In past the extension agents face difficulties in facilitating direct contact with farmer clients and with researchers due to the physical distances involved and lack of transportation needed for their mobility, but now the use of Information and Communication Technologies offers excellent possibilities, for strengthening research extension systems. Agricultural extension is one of the most important sectors in which ICT have particularly significant impact because it is solely depending on information dissemination and technology transfer (Ballantyne and Bokre, 2003). The frontline extension workers have direct communication between farmers and other actors in the extension of agricultural knowledge and information systems; they have great scope to make use of ICT to access expert knowledge or other types of information that could facilitate the accomplishment of the farmer's routine activities (Fawole and Olajide, 2012). Making frequent access of e- agriculture by the agricultural extension workers, they will able to gather much needed agricultural information (i.e., pre-harvest and post-harvest information, pricing, weather conditions among others) that can boost agricultural productivity (Awuor et al., 2013). With limited SAAOs disseminating quality information to the farmers we need to adopt e-agriculture as an effective tool. As the Sub-Assistant Agriculture Officers (SAAOs) are the prime outlet of agricultural information for the farmers, so it is necessary to know to what extent the extension workers are using e-agriculture now.

The objectives of this study are: a) to determine and describe the extent of communication exposure of Sub-Assistant Agriculture Officers (SAAOs) towards e-Agriculture. b) to identify the factors contributing the extent of communication exposure of Sub-Assistant Agriculture Officers (SAAOs) towards e-agriculture. c) to identify some constraints of communication exposure towards e- agriculture. d) to identify the device preference in using e-agriculture by the SAAOs.

\section{MATERIALS AND METHODS}

The study was conducted in Khulna district which consist of nine upazilas such as Phultala, Terokhada, Dumuria, Rupsa, Dighalia, Paikgaccha, Batiaghata, Dacope and Koyra upazilas. From nine upazilas, five upazilas (Phultala, Dumuria, Rupsa, Dighalia, Batiaghata) were purposively selected as the locale of the study as these are close to city and may have greater access to e-agriculture.

\section{Population and sample of the study}

Total number of SAAOs in Dumuria, Rupsa, Dighalia, Batiaghata and Phultala upazilas of Khulna district were 108 which constitute the population of the study. Out of this population, several 100 (93\%) respondents were selected as the sample of the study. With the consideration of population size $=108$, confidence interval=99, margin of error $=5$ the required number of sample size was 94. Selected sample size can exceed the required sample size. Distribution of population and sample are shown in Table 1.

\section{Collection of data}

In order to amass pertinent information, an interview schedule was prepared that contained both close and open type questions. Appropriate technique and measurement were applied to ensure correct responses of the variable concern. Data were collected from the respondents through personal contact by the researcher himself. The researcher made all possible efforts to establish rapport with the respondents so that they could feel easy to respond to the questions contained in the schedule. Data collected from the respondents were coded, compiled, tabulated, and analyzed in accordance with the objectives of the study. Qualitative data were converted into quantitative form by assigning suitable score whenever needed. The biasness of usage or uniformity of interview was prohibited. 
Statistical tests

Descriptive statistical methods like range, mean, percentage distribution and standard deviation were used in describing the dependent and independent variables. For clarity of understanding, tables were used in presenting data. For exploring the relationship between the selected characteristics of the SAAOs with their communication exposure towards e-agriculture Pearson's Product Moment Coefficients of correlation $(r)$ and regression analysis were used. Throughout the study $P<0.05$ as $95 \%$ of probability was used as a basis for rejecting or accepting the null hypothesis. The SPSS v16.0 (statistical package for social sciences) was used to perform data analysis.
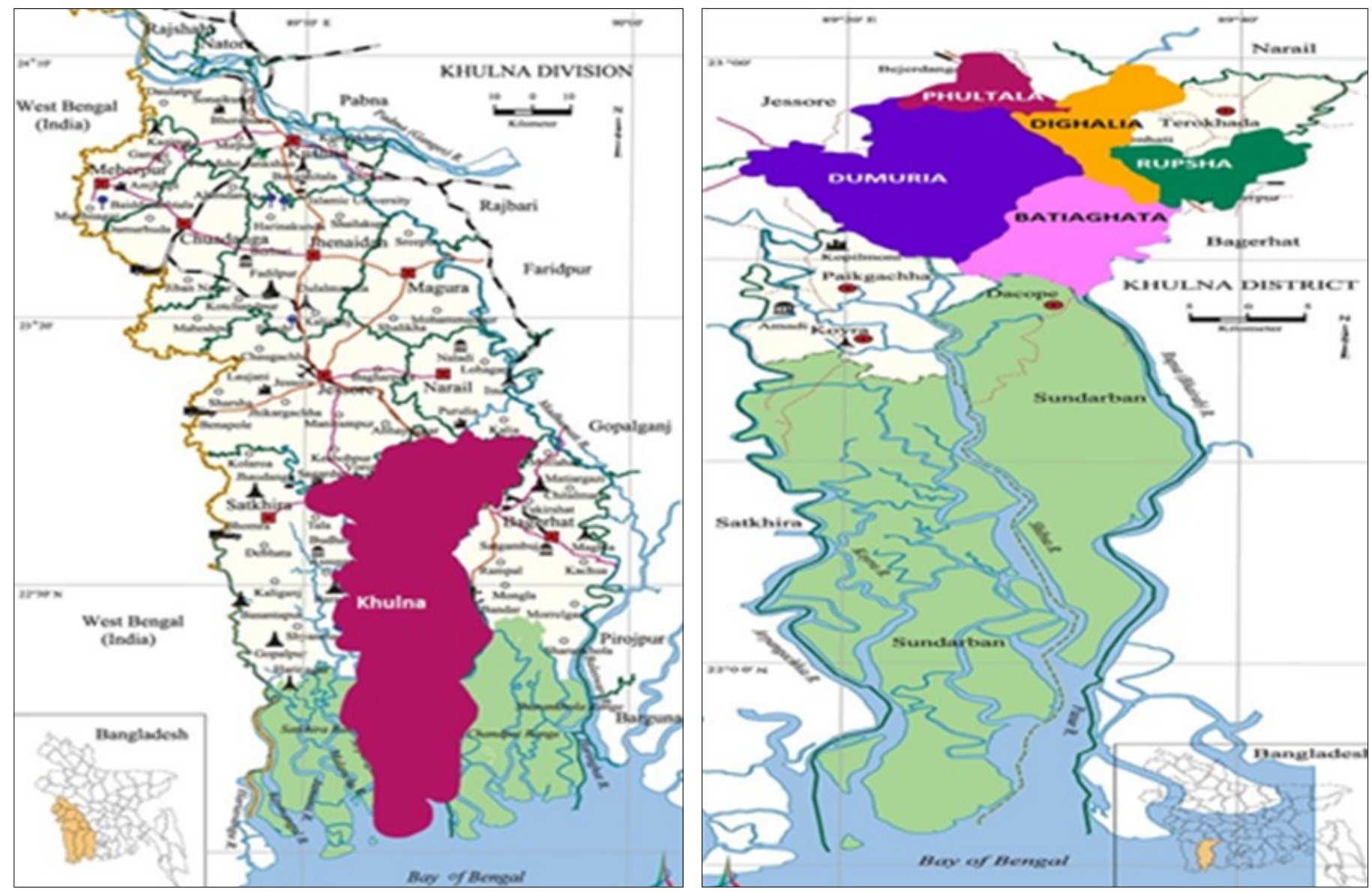

Figure 1. The first map 1 (a) showing the location of Khulna division in Bangladesh (inset) and Khulna district in the division. Figure 1 (b) shows the five selected study areas (upazilas) in Khulna district (Source: Banglapedia, National Encyclopedia of Bangladesh, 2011).

Table 1. Distribution of population and sample from Dumuria, Rupsa, Dighalia, Batiaghata and Phultala upazilas of Khulna district.

\begin{tabular}{clcc}
\hline District & Upazilas & Population & Sample \\
\hline & Dumuria, & 42 & 38 \\
& Rupsa, & 15 & 14 \\
Khulna & Dighalia, & 17 & 21 \\
& Batiaghata & 22 & 11 \\
Total & Phultala & 12 & 108 \\
\hline
\end{tabular}




\section{RESULTS AND DISCUSSION}

\section{Socio-economic characteristics of the SAAOs}

In the present study, seven characteristics of SAAOs were selected for investigation. These characteristics were age, monthly income, service experience, training exposure, job satisfaction, knowledge on e-Agriculture and organizational technological support. The study revealed that maximum (88\%) SAAOs of this area were middle to old aged. An old aged person usually showed reluctance to use e-agriculture related media. An investigation conducted by Salau and Singbe (2008) revealed that the elderly people might be less interested in the use of hi-tech innovations in field level work. As the SAAOs are middle to old aged so that highest portion (53\%) of SAAOs has long service experience. Naturally with the increase of age, service experience is increased. As the age and service experience increased most of the SAAOs tend to become less active and does not show interest in adopting newer technologies regarding their professional field. This may have contributed to form negative relationship with service experience and their communication exposures towards e-agriculture. It has also a positive side because experience makes a person more skilled and competent in his own work. Surprisingly it was found that a one-third of (75\%) SAAOs had no training on e-agriculture. DAE is still in introductory stage of e-agriculture. So, a very few projects addressed e-agriculture. That's why most of the SAAOs had no training on e-agriculture. It was also happened because of their aging condition; they showed unwillingness to get any relevant training. It is well known that training plays vital role for the development of knowledge, skill and attitude of a person, which makes him more capable and competent and helps an individual participate more in the development process more cheerfully with confidence. Maximum (41\%) SAAOs had high income.

Because most of the SAAOs were old aged, so that according to increase their age SAAOs are become more experienced and well salaried. The job satisfactory level of maximum (67\%) SAAOs were medium, because they are experienced in job but less competent in using ICTs for agricultural cultivation purpose. Knowledge and perception of any individual increases his/her awareness, mental alertness makes him/her familiar or acquaint with facts, objects, concepts, or practices and helps one to become rational which in turn increases his adoption rate of a new technology (Chen et al., 2018). But in this area majority (55\%) of SAAOs has medium knowledge in e-agriculture, the main reason of this is e-agriculture is a newer concept in Bangladesh and DAE has a very few trainings on e-Agriculture (Table 2). According to Prodhan and Afrad (2014), more than $84.4 \%$ of the respondents had medium to high knowledge towards ICT utilization because most of the respondents be aware of that extension work can be greatly enhanced by ICT and Knowledge of ICT use has a great significance in agricultural development. Ahmadpour et al. (2016) indicated the knowledge on e-learning improves possibility to adopt e-learning training on the job in the extension workers of Iran. Arokoyo (2005) also identified high level of illiteracy as a serious constraint to ICT utilization by extension workers and farmers. However, it is observed that an overwhelming majority (80\%) of respondents in the study area had less to moderate organizational technical support from different relevant GOs and NGOs, which is also a constraint for the SAAOs to develop their efficiency in e-agriculture sector.

Table 2. Socio-economic characteristics of the SAAOs $(n=100)$.

\begin{tabular}{|c|c|c|c|c|}
\hline Characteristics & Categories & Percentage & Mean & SD \\
\hline & Young aged (up to 35 years) & 13 & & \\
\hline \multirow[t]{3}{*}{ Age } & Middle aged (36-45years) & 34 & 45.44 & 8.74 \\
\hline & Old aged ( $>45$ years) & 53 & & \\
\hline & Short (up to 10 years) & 22 & & \\
\hline \multirow[t]{3}{*}{ Service experience } & Medium (11-20 years) & 25 & 21.36 & 11.10 \\
\hline & Long (above 20 years) & 53 & & \\
\hline & No training ( 0 day) & 75 & & \\
\hline \multirow{4}{*}{ Training experience } & Low training (1-7 days) & 19 & & \\
\hline & Medium training (8-15 days) & 4 & 2.04 & 5.11 \\
\hline & High training (above 15 days) & 2 & & \\
\hline & Low income (up to 25 ) & 39 & & \\
\hline \multirow[t]{3}{*}{ Monthly income } & Medium income (26-35) & 20 & 30.45 & 9.04 \\
\hline & High income (above>36) & 41 & & \\
\hline & Low job satisfaction (up to 10 ) & 10 & & \\
\hline \multirow[t]{3}{*}{ Job satisfaction } & Medium job satisfaction (11-15) & 67 & 13.75 & 2.37 \\
\hline & High job satisfaction (above>16) & 23 & & \\
\hline & Low knowledge (up to 7) & 36 & & \\
\hline \multirow[t]{3}{*}{ Knowledge on e-agriculture } & Medium knowledge (8-15) & 55 & 8.52 & 4.76 \\
\hline & High knowledge (above 15) & 9 & & \\
\hline & Less support (up to 5) & 9 & & \\
\hline \multirow[t]{2}{*}{ Organizational support } & Moderate support (6-11) & 71 & 9.01 & 3.05 \\
\hline & High support (above>12) & 20 & & \\
\hline
\end{tabular}


Table 3. Distribution of the respondents according to their communication exposure towards e-agriculture.

\begin{tabular}{|c|c|c|c|c|}
\hline \multirow{2}{*}{ Categories } & \multicolumn{2}{|c|}{ Respondents } & \multirow{2}{*}{ Mean } & \multirow{2}{*}{ SD } \\
\hline & Number & Percent & & \\
\hline Low communication exposure (up to 5) & 60 & 60 & \multirow{4}{*}{5.74} & \multirow{4}{*}{3.49} \\
\hline Medium communication exposure $(6-10)$ & 28 & 28 & & \\
\hline High communication exposure (above $>1$ ) & 12 & 12 & & \\
\hline Total & 100 & 100 & & \\
\hline
\end{tabular}

Table 4. Regression coefficients between communication exposures towards e-agriculture of the respondents with their selected characteristics.

\begin{tabular}{lllllll}
\hline Independent variables & B & SE & B & t & P & VIF \\
\hline Constant & 4.164 & 1.090 & & 3.822 & 0.000 & \\
Training exposure & 0.205 & 0.055 & 0.301 & 3.758 & 0.000 & 1,542 \\
Knowledge on e-Agriculture & 0.351 & 0.059 & 0.479 & 5.975 & 0.000 & 1.550 \\
Income & -0.060 & 0.028 & -0.156 & -2.187 & 0.031 & 1.228 \\
$\mathrm{R}^{2}=0.775$ & Adj. $\mathrm{R}^{2}=0.601$ & \multicolumn{2}{c}{$\mathrm{F}=48.23$} & & $\mathrm{P}<0.000$ & \\
\hline
\end{tabular}

Communication exposure of agricultural extension workers towards e-agriculture

The use of information and communication technology (ICT) is becoming progressively more widespread throughout various sectors including education, business as well as agriculture (Olowa, 2012). ICT as an extension tool could enhance the flow of information in the application of agricultural extension services. Communication exposure of SAAOs towards e-agriculture scores ranged from 3 to 17 against the possible range of 0 to 36 . Based on observed maximum and minimum communication exposure score and number of categories, the following categories were formulated in the Table 3.

Results furnished in table 3 shows that an overwhelming majority (88\%) of respondents in the study area had low to medium communication exposure towards e-agriculture. It indicates that majority of the SAAOs are out using rarely or often of e-agriculture in our agricultural extension services. Possible reasons for low communication exposure may be lack of organizational policy support, lack of training on e-agriculture and lack of knowledge of SAAOs in e-agriculture. Mugwisi et al. (2015) found that there was a high prevalence of ICTs to the extension workers in Zimbabwe (63\% had computer in office) and they used online database, journals, internet, e-mails, data storage, video recorder, and information management. This finding suggests extension workers in Bangladesh are far behind the extension agents of Zimbabwe in terms using ICTs in agriculture. It is a wake-up call for government agricultural extension services in Bangladesh.

Regression coefficients between communication exposures of the respondents with their selected characteristics

For predicting the contribution of the factors in the communication exposure of the respondents towards e-agriculture the enter regression method was applied. Among the seven characteristics, five characteristics namely age, income, service experience, training exposure, knowledge on e-agriculture were selected for regression analysis which had shown significance relationship with the communication exposure (dependent variable) in correlation coefficients. Regression coefficients of communication exposure of the respondents with their selected characteristics are shown in the Table 4.

Results furnished in Table 4, shows that the $R^{2}$ value is 0.775 and corresponding $F$ value is 48.23 which were significant at 0.000 levels. The $\mathrm{R}^{2}$ value indicating that 77.5 percent of the total variation in the communication exposure of SAAOs towards e-agriculture were explained by three variables included in the regression analysis. Age and service experience could not be explained in regression analysis because these two factors were showing co linearity in regression analysis. The results show that the communication exposure of the respondents towards e-agriculture is the function of Training exposure $(\beta=0.301)$, knowledge on e-agriculture $(\beta=0.479)$ and Income $(\beta=-0.156)$. The estimates revealed that knowledge on e-agriculture has the strongest contribution to the communication exposure of the respondents towards e-Agriculture. It was therefore, concluded that with the increase of knowledge on e-agriculture and training exposure, the communication exposure of the respondents will be positively influenced. Use of ICT enables extension workers to play complimentary roles of accessing and transferring relevant and pertinent information to farmers (Meera et al., 2004). Considering the urgency of training, there is strong suggestion for providing training to the extension workers and officers on the use of ICT (Leary and Berge, 2006; Mugwisi et al., 2015). Extension agents must have knowledge on e-agriculture and need to understand the importance of these technologies for increasing their efficiency and productivity in relation to technology transfer (Sife et al., 2007). The results also indicated that income had negative contribution to the communication exposure. It is expected as those who had higher income (from salary mainly), were the old extension workers. This result is quite opposite to the findings of Yakubu et al. (2013) where with the increase of age and income, extension workers tend to use ICTs more than others. Again this finding is supported by Fawole and Olajide (2012), who found young-aged farmers tend to adopt ICTs than the old one which confirms the general disposition to ICT use that older people are generally least user of ICTs. 
Table 5. Distribution of the respondents according to their device preference score.

\begin{tabular}{llccccccc}
\hline & \multicolumn{7}{c}{ Name of preferred devices } \\
\cline { 3 - 8 } S.N. & $\begin{array}{l}\text { Digital communication } \\
\text { media }\end{array}$ & $\begin{array}{c}\text { Mobile } \\
(\%)\end{array}$ & $\begin{array}{c}\text { Laptop } \\
(\%)\end{array}$ & $\begin{array}{c}\text { PC } \\
(\%)\end{array}$ & $\begin{array}{c}\text { Tablet } \\
(\%)\end{array}$ & $\begin{array}{c}\text { Net book } \\
(\%)\end{array}$ & $\begin{array}{c}\text { Television } \\
(\%)\end{array}$ & $\begin{array}{c}\text { Radio } \\
(\%)\end{array}$ \\
\hline 1 & Website & 16 & 12 & 4 & 2 & 2 & NA & NA \\
2 & E-mail & 8 & 9 & 4 & 1 & 2 & NA & NA \\
3 & Video chatting & 11 & 3 & 1 & 0 & 0 & NA & NA \\
4 & Phone call & 95 & 0 & 0 & 5 & 0 & NA & NA \\
5 & Social media & 43 & 4 & 1 & 0 & 0 & NA & NA \\
6 & Television program & 3 & 0 & 5 & 1 & 0 & $17 \%$ & NA \\
7 & Radio program & 7 & 0 & 0 & 0 & 0 & NA & $9 \%$ \\
8 & Application (Apps) & 15 & 0 & 0 & 0 & 0 & NA & NA \\
9 & Documentary & 2 & 0 & 3 & 0 & 0 & 0 & NA \\
10 & Online newspaper & 19 & 5 & 1 & 0 & 0 & NA & NA \\
11 & SMS & 33 & 0 & 0 & 0 & 0 & NA & NA \\
12 & MMS & 11 & 0 & 0 & 0 & 0 & NA & NA \\
\hline
\end{tabular}

NA= Not applicable.

Table 6. Constrains of communication exposure towards e-agriculture as faced by the respondents $(n=100)$.

\begin{tabular}{lcc}
\hline Personal constraints & Percent of respondents & Rank \\
\hline Unfamiliarity of extension worker with e-agriculture application & 79 & 71 \\
Lack of skill to use e-agriculture & 53 & 2 \\
Lack of knowledge on e-agriculture application & 44 & 3 \\
Lack of interest to use e-agriculture & 41 \\
Language problem for old aged extension worker to use e-Agriculture & Percent of respondents \\
& \\
Organizational constraints & 89 \\
& 81 \\
Lack of training on e-agriculture & 51 \\
Lack of instrument (laptop, computer, tab) & 2 \\
Poor internet facility & 4 \\
Weak mobile networking system & 3 \\
Lack of ICT related communication in DAE & 32 \\
\hline
\end{tabular}

Preferred devices in using e-agriculture by the respondents Agriculture is one of the vital sectors in which ICT can be used reasonably in transferring the modern agricultural technologies to the farmers (Prodhan and Afrad, 2014). Information and communication technology in agriculture includes internet, e-mail, cell phone, computers, radio, television, wireless communication tools, audio visuals, digital camera, CD-ROM, printer, fax which helps in timely communication at agricultural extension services (Fawole and Olajide, 2012; Mugwisi et al., 2015). To know the device preference by the SAAOs in using e-agriculture twelve media were selected against 7 devices. Device preference by the agricultural extension worker in using selected e-agriculture media is presented in Table 5.

From data furnished in the Table 5, it was very clear that among those media mobile was mostly used device for making phone call (95\%), using social media (43\%) and for sending SMS (33\%). Mobile phone was also considered effective ICT device by the extension workers and researchers in Zimbabwe and around half of the agents used mobile phone for communicating agricultural information (Mugwisi et al., 2015). The $2^{\text {nd }}$ most preferred device by the SAAOs was laptop and it was mostly used in browsing website (12\%) and sending e-mail (9\%). PC was less preferred device than laptop. Tablet computer was mostly used in making phone call (5\%) and website browsing (2\%). Net book was the least preferred device and used for only browsing website and email. However, television and radio program were also enjoyed from mobile phone and PC. It was surprising to note that only 15 percent agents used mobile apps to gather agricultural information. Now-a-days, there are a good number of apps available in Google play store for android phones. Lack of introduction and training may be responsible for such poor exposure. Less use of website, documentary, apps, e-mail and high use of phone call suggest that extension agents are comfortable with readily available information from one to one communication either from peers or from experts rather than self-quest for new information.

Constraints of communication exposure towards e-agriculture as faced by the respondents

The major constrains faces by the SAAOs were classified into two categories such as personal constrains and organizational constraints. Constraints faced by the SAAOs in respect of, "communication exposure towards e-agriculture" were constructed in Table 6. 
Constraints furnished in Table 6, indicate that "unfamiliarity of extension worker with e-agriculture application", "lack of skill to use e-agriculture" and "lack of knowledge on e-agriculture application" were the most cited personal constraints of communication exposure towards e-agriculture. On the other hand, "lack of training on e-agriculture", "lack of ICT instrument", and "poor internet facility" were the most crucial organizational constraint of using e-agriculture. Lack of skill was not a constraint for Nigerian extension officers rather poor infrastructure, poor connectivity, poor electricity, high price of ICT, and lack of ICTs hindered access to ICT (Akpabio et al., 2007). Another study with farmers by Fawole and Olajide (2012), from Nigeria confirmed farmers' illiteracy constrained them to use ICT. Overall, it can be said that extension agents in study area still struggles with very basic access, knowledge and use related problems in implementing e-agriculture.

\section{Conclusion}

Despite inevitable future, e-agriculture has not gained much land in government extension service in Bangladesh. Still a good number of extension agents in this study are not well acquainted with e-agriculture and possess insufficient knowledge in ICTs. The situation even worse when we consider two third of the extension agents have no training on e-agriculture. Most of the agents were middle to old aged who generally prefer mobile phone to have interpersonal communication rather than sophisticated use of smart phones like using agricultural applications. Government agricultural extension service provider in Bangladesh, the DAE needs periodic recruitment to inject new ideas, skills, and spirit in the service. Devices preference for using e-agriculture shows the agents are a very basic user of ICT devices. Lack of skill, training, knowledge and availability of ICT devices hindered agents' exposure to e-agriculture. Organizational support through training on e-agriculture and providing more ICT devices along with introduction of digital library, creating digital contents and documentaries may help in increasing use of ICTs in agriculture by the extension agents.

Open Access: This is an open access article published under the terms and conditions of Creative Commons AttributionNonCommercial 4.0 International License which permits noncommercial use, distribution, and reproduction in any medium, provided the original author(s) if the sources are credited.

\section{REFERENCES}

Ahmadpour, A. Mirdamadi, S.M. and Soltani, S. (2016). Attitude towards on-the-job e-learning: The case of agricultural extension workers in Iran. Journal of Agricultural Science and Technology, 18(1): 27-38.

Ahmed, T. (2007). A Study on Communication between Department of Agricultural Extension (DAE) and the Farmers of Bangladesh (MS Thesis). Swedish University of Agricultural Sciences, Sweden. https://stud.epsilon.slu.se/4256/1/ahmed_t_120607.pdf

Akpabio, I.A. Okon, D.P. and Inyang, E.B. (2007). Constraints affecting ICT utilization by agricultural extension officers in the Niger Delta, Nigeria. The Journal of Agricultural Education and Extension, 13(4): 263-272. https://doi.org/10.1080/13892240701630986
Arokoyo, T. (2005). ICTs application in agricultural extension service delivery. In: S.F. Adedoyin (Ed.), Agricultural Extension in Nigeria. Llorin, Nigeria: Agricultural Extension Society of Nigeria. 245-251.

Asfaw, S., Shiferaw, B., Simtowe, F. and Lipper, L. (2012). Impact of modern agricultural technologies on smallholder welfare: evidence from Tanzania and Ethiopia. Food Policy. 37(3): 283-95, https://doi.org/10.1016/j.foodpol.2012.02.013

Awuor, F., Kimeli, K., Rabah, K. and Rambim, D. (2013). ICT solution architecture for e-Agriculture. Paper presented at the IST-Africa, 2013 Conference Proceedings, Nairobi. https://ieeexplore.iee.org/document/6701752

Ballantyne, P. and Bokre, D. (2003). ICTs: Transforming Agricultural Extension? Report of an iNARSe-discussion, Retrieved October 15, 2007. http://www.livelihoods.org/info/docs/inars_Supersummary.pdf

BBS, (2014). Statistical Yearbook Bangladesh. Bangladesh Bureau of Statistics Division, Ministry of Planning, Govt. Republic of Bangladesh, Dhaka.

Bhalekar, P., Ingle, S. and Pathak, K. (2015). The study of some ICT projects in agriculture for rural development of India, Asian Journal of Computer Science and Information Technology 5(1): 5-7.

Chen, Z., Zhang, J. and He, K. (2018). Technical perception, environmental awareness and adoption willingness of agricultural cleaner production technology. Chinese Journal of Eco-Agriculture, 26(6): 926-936, https://doi.org/10.13930/j.cnki.cjea.171051

FAO (2015). Success stories on information and communication technologies for agriculture and rural development. Food and Agriculture Organization of the United Nations Regional Office for Asia and the Pacific Bangkok. http://www.fao.org/3/a-i4622e.pdf

Fawole, O.P. and Olajide, B.R. (2012). Awareness and use of information communication technologies by farmers in Oyo State, Nigeria. Journal of Agricultural $\begin{array}{llll}\text { and } \quad \text { Food } 13(4): \text { Information, } & \end{array}$ https://doi.org/10.1080/10496505.2012.717003

Ghogare, S.A. and Monga, P.M. (2015). "E-Agriculture" Introduction and Figuration of its Application. International Journal of Advanced Research in Computer Science and Software Engineering, 5(1): 44-47.

Jensen, R. (2007). The Digital Provide: Information (Technology) Market Performance, and Welfare in the South Indian Fisheries Sector, The Quarterly Journal of Economics, 122(3): 879-924, https://doi.org/10.1162/qjec.122.3.879

Joyous, S. and Paul, E. (2016). Social Factors That Influence Use of ICT in Agricultural Extension in Southern Africa, International Journal of Agriculture. 6(2): 15-20.

Leary, J. and Berge, Z.L. (2006). Trends and Challenges of e-learning in National and International Agricultural Development. International Journal of Education and Development Using ICT, 2(2): 26-33.

Meera, S.N., Jhamtani, A. and Rao, D.U.M. (2004). Information and Communication Technology in Agricultural Development: A Comparative Analysis of Three Projects from India. Agricultural Research and Extension Network Paper No.135, pp 14.

Mugwisi, T., Mostert, J. and Ocholla, D.N. (2015). Access to and Utilization of Information and Communication Technologies by Agricultural Researchers and Extension Workers in Zimbabwe. Information Technology for Development, 21(1): 67-84, https:// doi.org/10.1080/02681102.2013.874317

Olowa, O.W. (2012). An Assessment of Internet Uses, Practices and Barriers for Professional Development by Agricultural Science Teachers in Lagos State. Journal of Education Research International, 12: 7-11, https://doi.org/10.1155/2012/503264

Prodhan, F.A. and Afrad, S.I. (2014). Barriers and Preparedness of Agricultural Extension Workers towards ICT Utilization in Gazipur District of Bangladesh (MS thesis). International Journal of Extension Education, 10: 1-9.

Prodhan, F.A. and Afrad, S.I. (2014). Knowledge and perception of extension Workers towards ICT Utilization in Agricultural Extension Service Delivery in Gazipur District of Bangladesh, International Journal of Agricultural Research, Innovation and Technology, 4(2): 46-52, https://doi.org/10.3329/ijarit.v4i2.22647

Reddy, K.A., J. Prasad, R. and Kumar, K.P.V. (2012). A study on agriculture informatics in Indian Context. International Journal of Computer, 55(12): 1-12.

Salau, E.S. and Saingbe, N.D. (2008). Access and utilization of information and communication technologies (ICTs) among agricultural researchers and extension workers in selected institutions in Nasarawa State of Nigeria, International Journal of Production Agriculture and Technology, 4(2): 1-11. http://patnsukjournal.net/Vol4No2/p1.pdf

Sife, A.S., Lwoga, E.T. and Sanga. C. (2007). New Technologies for Teaching and Learning: Challenges for Higher Learning in Developing Countries. International Journal of Education and Development Using Information and Communication Technology, 3(2): 57-67. 
Singh, K.M., Kumar, A. and Singh, R.K.P. (2015). Role of Information and Communication Technologies in Indian Agriculture: An Overview, International Journal of Munich Personal RePEC Archive, 14: 1-27, https://mpra.ub.uni-muenchen.de/62413/1/MPRA_paper_62413.pdf

Timmer, W.J. (1982). The human side of agriculture: theory and practice of agricultural extension: with special reference to developing rural communities in the tropics and sub-tropics. New York: Vantage Press. https://trove.nla.gov.au/version/26972434
World Bank (2011). ICT in Agriculture: Connecting Smallholders to Knowledge, Networks, and Institutions; World Bank: Washington, DC, USA. http://documents.worldbank.org/curated/en/522141499680975973/ pdf/117319-PUB-Date-6-27-2017-PUBLIC.pdf

Yakubu, D.H., Abubakar, B.Z., Atala, T.K. and Muhammed, A. (2013). Use of Information and Communication Technologies among Extension Agents in Kano State, Nigeria. Journal of Agricultural Extension, 17 (1): 162-173. 